$$
\begin{gathered}
\text { 도시 공원 야간경 관의 조성 과정 과 실태 분석 } \\
- \text { 여의도공원을 중심으로 - } \\
\text { 김현근" · 김아연 }
\end{gathered}
$$

\title{
Analysis of Urban Park Nightscape based on the Design-Construction Process and Current Status
} - Focused on Yeouido Park -

\author{
Kim, Hyun-Geun* $\cdot$ Kim, Ah-Yeon ${ }^{* *}$
}

\begin{abstract}
"Dept. of Landscape Architecture, Graduate School, The University of Seoul
** Dept. of Landscape Architecture, The University of Seoul
\end{abstract}

\begin{abstract}
Light has been an essential part of human life. The advancement of technology has changed cities' nightscape and night activities in a drastic way. Lighting has influenced the identity of a city while promoting a variety of civic nighttime cultural pursuits, yet lighting design has not been considered adequately in the field of landscape architecture. This study aims to analyze the current status of lighting in urban parks through interviews with professionals, literature and regulation reviews, analysis of design documents and a field survey focused on Yeouido Park in Seoul. The findings and improvement directions are as follows. First, it is necessary to develop a specific lighting design method in order to avoid a marginalized, passive approach such as light fixture installation. Second, the existing standards of illuminance by KS A 3011 regulating only horizontal illuminance has turned out not to evaluate the current nightscape of urban parks properly. Therefore the criteria and guideline for analysis and design for nightscape should be articulated. Third, there are no design or management strategies to consider the changing landscape of urban parks, which is necessary due to the changing characteristics of park ecosystems. Lastly, detailed guidelines for distinguished spaces in urban parks should be studied and suggested.
\end{abstract}

Key Words: Landscape Lighting, Park Planning and Design Process, Lighting Design, Illumination

\section{국문초록}

빛은 인간 생활을 결정하는 중요한 요소이다. 인류가 인공적으로 빛을 다룰 수 있게 된 이래 조명은 도시의 야간 문화와 경관을 획기적으로 바꾸어 놓았다. 야간 경관은 도시의 정체성에 지대한 영향을 미친다. 시민들의 야간 활동이 늘어나면서 조명에 대한 다양한 요구가 늘어나는 추세이지만, 정작 경관을 다루는 조경 분야의 계획 - 설계과정에서 조명

Corresponding author: Ah-Yeon Kim, Dept. of Landscape Architecture, The University of Seoul, Seoul 02504, Korea, Tel.: +822-6490-2845, E-mail: ahyeonkim@uos.ac.kr 
계획은 비중 있게 다루어지지 않았다. 본 연구는 우리나라 도시공원의 야간경관의 실태를 분석하기 위해 공원의 계획 및 조성 과정과 제도적 측면의 문제점을 파악하고, 여의도공원을 대상으로 도면 분석과 현장 조사를 통해 문제점을 도출하였다. 현재 도시공원의 야간경관과 관련한 실태 분석의 결과는 다음과 같다. 첫째, 공원의 계획·설계 과정에서 조명계획은 설비 분야에 포함되어 개략적인 수준으로만 다루어져왔고, 이는 실제 공원의 단조로운 야간경관을 초래했다 고 볼 수 있다. 따라서 공원의 분석-계획-설계-시공-관리 과정에서 야간경관의 연출을 적극적으로 수용할 수 있는 방법론이 개발되어야할 것이다. 둘째, 현재 도시공원에 적용 가능한 기준은 한국산업규격(KS A 3011)의 수평조도 규정에 그치고 있어 야간경관 평가와 계획의 세부 기준 항목을 다양하게 개발할 필요가 있다. 셋째, 성장하는 수목과 복합적인 자연생태계 의 특성을 고려할 수 있는 야간경관 설계 및 관리 방안이 필요하다. 넷째, 공원의 공간별 특성에 맞는 세부 디자인 가이드라 인과 관련 기준이 필요하다.

주요어: 경관조명, 공원 계획설계과정, 조명 설계, 조도

\section{I. 서론}

\section{1. 연구배경과 목적}

도시의 공공공간 중 공원은 일반적으로 해가 지는 동시에 이 용이 현저히 줄어드는 곳으로 간주되었다. 공원의 계획 및 설 계는 주간 이용을 전제로 진행되어 왔고, 이는 야간 경관에 대 해 크게 비중을 두지 않았다는 사실을 반증한다(Kim, 2013). 하지만 시민들의 야간 생활 패턴이 변하면서 여가나 운동 등의 활동이 야간에 이루어지는 비율이 급증하고 있으며, 이러한 생 활 패턴의 변화에 힘입어 최근 조명은 밤에 도시를 밝히는 필 수 요소이자 도시의 이미지를 좌우하는 중요한 경관 요소로 각 광받고 있다. 야간 범죄에 노출되기 쉬운 위험한 장소로 여겨 졌던 공원을 다시금 일상 공간으로 돌려놓으려는 노력들이 활 발하게 이어지고 있다.

일몰 이후 도시에서 가장 우선시 되는 요소는 안전성이다. Choi and $\operatorname{Kim}(2001)$ 는 도시근린공원의 야간 이용에 있어서 조 명의 적절한 활용이 안전성 증대 효과로 이어진다는 것을 발견 하였다. Lee(2015)는 대구시 근린공원을 대상으로 CPTED 개 념을 적용하기 위해서는 조명 확충과 함께 수목에 대한 정비를 통해 가시성을 높이는 것이 이용객들의 심리적 안전성을 높인 다는 결과를 도출하였다. 그러나 관행적인 공원의 조명 계획은 비용 절감 차원에서 최소한의 조도 기준을 맞추는 수준으로 의사결정이 이루어왔고, 설계와 시공 과정에서도 전기설비자 에게 위임되는 등 공원의 계획 과정에서 종합적으로 다루어지 지 못해왔던 것이 현실이다. 전반적으로 조명 기구에 대한 설 치와 관리 수준이 미흡한 상황에서 경관조명 계획의 전체적인 수준 역시 높지 않은데, 야간 환경의 가장 큰 문제인 안전성은 더 밝게 하는 단순한 방법으로 해결되지는 않으며, 빛의 복잡 성에 대한 충분한 이해를 토대로 안전의 측면과 미적 측면을 동시에 만족시킬 수 있는 방법을 통해 종합적으로 접근해야 한다(Jo, 2001).
2011년 1월, 국내 최초로 서울시가 “빛공해 방지 및 도시조명 관리 조례'를 시행하였고, 이후 2012년 2월 2일 '인공조명에 의 한 빛공해 방지법’이 공포되었다. 이는 과도한 빛의 이용이 도 시민이나 환경에 부정적인 영향을 끼치는 것을 방지하기 위해 제정된 법으로, 야간 환경을 바라보는 새로운 시각을 가지게 된 계기라고 할 수 있다.

새로운 법령 시행 이후 이루어진 연구들을 살펴보면, 서울 시 강동구 주거지 일대를 대상으로 기존에 조성된 가로조명에 대한 문제점을 분석하고, 개별 가로조명의 투광 방식에 의한 빛의 분포 각도와 면적이 중요하다는 사실을 밝히거나(Hwang, 2011), 도시 공간 내의 도로, 주택가 그리고 산책로 조명의 배 광 방식에 대한 실태 분석을 토대로 개선 방향을 모색(Lee, 2013)하는 등 조명을 주변 지역과의 관계성 속에서 파악하는 연구들이 진행되고 있다. 그러나 주거지 침입광을 규제하는 '인 공조명에 의한 빛공해 방지법' 만으로는 생태계와 시민들의 활동, 그리고 야간 경관의 미적 측면이 복합적으로 얽혀있는 공원의 야간경관을 규정하는데 한계를 가지고 있다. 이러한 측면에서 볼 때 빛이 생태계에 끼치는 영향은 상당하지만, 야 간조명과 생태계에 대한 국내의 연구는 미비한 상황이다. Choi (2008)는 야간조명이 생태계에 미치는 영향에 관한 연구를 진 행하였으나, 벼를 포함한 농작물에 한정되어 도시 공원에 직접 적용하기에는 한계가 명백하다.

살펴본 바와 같이 도시공원의 야간경관은 안전성에서부터 빛공해 방지, 공원의 생태적인 측면, 도시 정체성에 기여하는 야간 경관 연출, 야간 여가 활동 지원 등 다양한 요소를 복합적 으로 고려해야 하지만, 공원을 중심으로 한 야간경관에 대한 연구는 매우 부족한 상황이다.

본 연구는 우리나라 도시공원 야간경관의 실태를 진단하고 분석하는 것을 목적으로 하며, 현 상황의 원인을 규명하기 위 해 공원의 계획-조성 과정과 제도적 측면의 문제점을 함께 파 악하고자 하였다. 이러한 시도는 도시공원의 야간 경관에 대한 개념이 명확히 정립되어 있지 않은 현 시점에서 주간 이용에 
초점이 맞춰져 있던 도시공원 계획-설계 과정을 야간으로 확장 하고, 세부 분야로서의 야간경관에 대한 계획원칙과 설계지침 을 수립하기 위한 구조적 틀을 제공할 수 있을 것이다.

\section{II. 이론적 고찰}

\section{1. 야간경관과 경관조명}

경관(景觀)이란, 자연을 비롯하여 주변을 이루는 건축물을 포함한 인공적인 요소와 인간의 생활상으로 이루어진 한 지역 의 환경적 특징을 나타내는 것으로, 이는 흔히 우리가 경관이 라 할 때 떠올리는 경치나 풍경과 같은 시각적 요소 이외에 해 당 지역에 사는 사람들의 생활방식과 같은 문화적인 요소를 포 함하는 종합적인 의미를 지닌다(Lee, 1998). 이러한 개념을 토 대로 이루어지는 경관 계획은 물리적 공간 환경과 사람들과의 관계성을 포함한 도시 전체에 대한 이해를 바탕으로 이용자 인 사람들에게 시각적인 심미성을 중심으로 한 경험의 기회를 제공해야 한다. 특히 경관조명은 주간의 물리적 경관을 야간 에 빛을 통해 연출하고 규정하는 기능을 하며, 빛을 통해 공간 을 재구성하는 행위를 통해 형성된 모습을 야간경관이라 한 다(Yang, 2016).

Landscape Design Standards(2002)는 경관조명을 전원이나 도시적 환경의 옥외공간에서 환경성, 안정성, 쾌적성, 그리고 부드러운 분위기 연출 등의 목적과 옥외공간의 경관구성요소 로서 연출하는 것으로 정의하였고, Moyer(1992)는 경관조명의 목적을 안전, 보안, 흥미로운 경관의 창출이라고 하였다.

Korean Landscape Council(2011)은 경관조명의 종류를 보행 자와 차량 등의 안전을 확보하는 가로등 및 보안등과 거리에서 광고나 시선을 끌기 위한 간판, 네온사인 등의 상업적인 목적 의 조명, 그리고 기념물, 역사적 건조물과 교량, 공원, 수목, 분 수, 일루미네이션 등으로 분류하고 있다. Yang(2016)은 경관조 명을 "야간에 있어 단순히 빛을 이용하여 대상물을 주간과 동 일하게 인식시키는 것에 머무르지 않고, 대상을 알기 쉽게 하 여 쾌적성을 확보하는 동시에 주간에는 보이지 않는 경관의 조 형미나 입체감, 아름다움 등의 미적 효과를 강조"하는 것으로 정의하고 있는데, 경관조명에 있어서 중요한 점은 빛과 주변 의 관계성이라 할 수 있다. 그러나 빛과 사람 그리고 외부공간 의 관계는 쉽게 규정할 수 없기 때문에 특정 장소의 미적 특 성, 유용성, 쾌적성을 확보하기 위해서는 빛이 비추어지는 곳의 모든 대상들의 특성과 상호관계가 반드시 파악되어야 한다. 더 불어, 빛과 인간의 심리적, 생리적인 면에 대한 이해가 필요하다 (Divall, 2000). 본 연구에서는 도시공원의 야간경관을 이용자 측면에서의 안전성과 쾌적한 조명환경 그리고 공원의 생태적 인 특성을 지닌 복합적인 개념으로 정의하고, 이러한 측면에서 현재 도시공원의 야간경관 실태를 파악하고자 하였다.

\section{2. 관련 기준 및 법령}

1) 국내 기준 및 법령

국내에는 공인된 조명 단체 혹은 학회에서 제시하는 경관조 명 지침이 별도로 없으며, 도시공원에 적용할 수 있는 조명관련 기준은 한국산업규격의 KS A 3011 뿐이다.

$\mathrm{KS}$ A 3011은 '조도'를 우선적인 기준으로 제시하고 있다 (Korean Industrial Standards, 1993). 그 중 공원에 해당하는 두 가지 항목에 대한 조도 기준이 명시되어 있는데, '전반 조 명'은 6-10-15 lx이며, '주된 장소'는 15- 20-30 lx이다(Table 1 참조). 이 조도 기준은 공원 내의 공간별 기능이나 공원 인접지 역의 특성 및 관계성을 전혀 고려하지 않은 일반적인 지침이라 고 볼 수 있다. 또한 KS A 3011은 1993년에 제정된 것으로 25 년이 넘는 기간 동안의 사람들의 생활 패턴과 변화와 공원 이 용자의 행태 변화를 포함한 전반적인 시대변화를 반영한다고 볼 수 없다. 더불어, 조도 역시 수평면 조도 $\left(\mathrm{E}_{\mathrm{H}}\right)^{1)}$ 만 규정하고 있어 실제 이용자가 인지하는 경관의 입체적인 측면을 종합적 으로 규정하고 있지 못하며, 이는 해외 사례에서 제시하는 연 직면 조도 $\left(\mathrm{E}_{\mathrm{V}}\right)^{2)}$ 에 관한 기준을 통해 보완해야할 것이다.

더불어 조도의 측정 방법에 대해 다루고 있는 KS C 7612를 살펴보면 옥외의 경우, '바닥면 또는 지상면 $15 \mathrm{~cm}$ 이하'라는 기 준과 함께 '측정 영역을 동등한 크기의 면적으로 분할하고, 분 할선의 교점을 측정점으로 하여 전체적으로 10 50점이 되도 록 결정한다는 측정 기준이 제시되어 있으나, 적용에 있어서 해석의 여지가 많아 혼선의 우려가 크다.

도시공원의 야간조명과 관련된 법으로는 $\mathrm{r}$ 도시공원 및 녹

Table 1. KS A 3011

\begin{tabular}{|c|c|c|c|}
\hline \multicolumn{4}{|c|}{$\begin{array}{l}\text { Classification of illuminance and value of illuminance } \\
\text { according to activity types(KS A } 3011 \text { table 9) }\end{array}$} \\
\hline Activity type & Classification & Range(lx) & Reference \\
\hline $\begin{array}{l}\text { Distinguishable working place } \\
\text { in dark atmosphere }\end{array}$ & A & $3-4-6$ & \multirow{5}{*}{$\begin{array}{l}\text { Light } \\
\text { throughout } \\
\text { the space }\end{array}$} \\
\hline $\begin{array}{l}\text { Low usage of place in dark } \\
\text { atmosphere }\end{array}$ & B & $6-10-15$ & \\
\hline $\begin{array}{l}\text { Common place in dark at- } \\
\text { mosphere }\end{array}$ & $\mathrm{C}$ & $15-20-30$ & \\
\hline $\begin{array}{l}\text { Place where temporary and } \\
\text { simple work performed }\end{array}$ & $\mathrm{D}$ & $30-40-60$ & \\
\hline Working place where & $\mathrm{E}$ & $60-100-150$ & \\
\hline $\begin{array}{l}\text { When performing with eyes } \\
\text { in high luminance condition } \\
\text { or huge objects }\end{array}$ & $\mathrm{F}$ & $150-200-300$ & $\begin{array}{l}\text { Light at } \\
\text { work plane }\end{array}$ \\
\hline \multicolumn{4}{|c|}{ Recommended levels of illuminance to outdoor facilities } \\
\hline \multicolumn{2}{|l|}{ Classification } & \multicolumn{2}{|c|}{ Class of illuminance } \\
\hline \multirow{2}{*}{ Park } & Whole area & \multicolumn{2}{|c|}{ B } \\
\hline & Main area & \multicolumn{2}{|c|}{$\mathrm{C}$} \\
\hline
\end{tabular}


지 등에 관한 법률」과 r 인공조명에 의한 빛공해 방지법」의 시 행규칙을 살펴볼 수 있다. '도시공원 및 녹지 등에 관한 법률 시 행규칙,에서 조명기구는 창고나 차고, 게시판, 표지판, CCTV 와 동일한 공원관리에 필요한 시설물로 정의되고 있다. 이는 현행 법령이 조명을 공원의 경관을 형성하는 수단이 아니라, 단순히 공원 관리적 차원에서 등기구라는 소극적인 정의에 기 반하고 있다는 사실을 보여준다(Table 2 참조).

2012년 2월 제정된 r인공조명에 의한 빛공해 방지법」은 무 분별하게 설치된 인공조명이 과도한 빛으로 사람에게 눈부심 현상을 유발시키고, 나아가 생태계에 끼치는 피해가 클 것을 우려해 과도한 조명 사용을 제한하기 위해 제정되었다. 해당법 시행령에 명시된 적용 공간은 도로, 보행로, 그리고 도시공원 및 녹지 등에 관한 법률에서 규정하는 공원녹지을 대상으로 하고 있으나, 시행 규칙에서 그 기준이 주거지 연직면 조도에 그치고 있어, 주거지와 면하지 않은 도시공원의 경우 관련법을 적용할 수 없는 한계점을 갖는다.

\section{2) 해외 기준 및 법령}

도시공원의 야간경관에 대한 해외 기준은 국제조명위원회 $\mathrm{CIE}$ (Commission Internationale de l'Eclairage), 미국에서 사용 하는 기준인 IES(Illuminating Engineering Society) 그리고 한국산업규격의 조도 기준을 수립할 당시 많은 부분을 참조했 던 JIS(Japanese Industrial Standards)를 살펴보았다.

(1) 국제조명위원회
국제조명위원회는 조명과 색채에 대한 국제적인 표준을 제 정하는 단체로 빛공해와 관련된 "옥외조명 설비에 따른 방해 광 규제 가이드(CIE 150:2003, Guide on the limitation of the effects of obtrusive light from outdoor lighting installations)" 를 제시하고 있다. 해당 가이드는 조명환경이 가져야할 가장 기본적인 사항으로, 주변 지역의 밝기에 따라 환경 구역을 크 게 4 개 지역으로 분류하고 있다(Table 3 참조). 또한 사람에 끼치는 영향을 고려해 주거지를 기준으로 연직면 조도에 해당 하는 기준을 제시하고 있는데, 특이한 점은 각 구역별로 다른 상한 기준을 시간대별로 나누어 일몰 전후로 구분하였다는 점 이다(Table 4 참조). 일몰 후에는 연직면 조도 기준이 최소 절 반 수준으로 낮게 제시된 것을 확인할 수 있다.

도시에서 통로는 도시 공간 곳곳을 이어주는 아주 중요한

Table 3. The environmental zone

\begin{tabular}{c|c|c|c}
\hline Zone & Surrounding & $\begin{array}{c}\text { Lighting } \\
\text { environment }\end{array}$ & Example \\
\hline E1 & Natural & Intrinsically dark & $\begin{array}{c}\text { National parks or } \\
\text { protected sites }\end{array}$ \\
\hline E2 & Rural & $\begin{array}{c}\text { Low district } \\
\text { brightness }\end{array}$ & $\begin{array}{c}\text { Industrial or residential } \\
\text { rural areas }\end{array}$ \\
\hline E3 & Suburb & $\begin{array}{c}\text { Medium district } \\
\text { brightness }\end{array}$ & $\begin{array}{c}\text { Industrial or residential } \\
\text { suburbs }\end{array}$ \\
\hline E4 & Urban & $\begin{array}{c}\text { High district } \\
\text { birghtness }\end{array}$ & $\begin{array}{c}\text { Town centers and } \\
\text { commercial area }\end{array}$ \\
\hline
\end{tabular}

Source: Commission Internationale de l'Eclairage(2003)

Table 2. Related domestic laws and acts

\begin{tabular}{|c|c|c|c|c|c|c|c|c|}
\hline Laws & \multicolumn{8}{|c|}{ Content } \\
\hline $\begin{array}{l}\text { Enforcement rule of act on } \\
\text { urban parks, greenbelts, etc. } \\
\quad \text { [attached Table 1] }\end{array}$ & \multicolumn{8}{|c|}{$\begin{array}{l}\text { 7. Park management facilities } \\
\text { warehouse } \cdot \text { garage } \cdot \text { bulletin board } \cdot \text { notice } \cdot \text { light facilities } \cdot \text { CCTV } \cdot \text { waste disposal site } \cdot \text { trash can } \cdot \text { water pipe, well, solar } \\
\text { energy source }(\text { limiting to install in buildings and parking lots), and other facilities required to manage parks }\end{array}$} \\
\hline $\begin{array}{l}\text { Enforcement decree of the } \\
\text { act on the prevention of } \\
\text { light pollution due to } \\
\text { artificial lighting } \\
\text { article 2(Scope of lighting } \\
\text { facilities) }\end{array}$ & \multicolumn{8}{|c|}{$\begin{array}{l}\text { Lighting fixtures defined in subparagraph } 2 \text { of article } 2 \text { of 'The act on the prevention of light pollution due to artificial lighting } \\
\text { (hereinafter referred to as the "Act") shall be any of the following fixtures: }\langle\text { Amended by Presidential Decree No. 25456, Jul } \\
\text { 14, 2014; Presidential Decree No. 25786, Nov. 28, 2014; Presidential Decree No. 27323, Jul. 6, 2016> } \\
\text { 1. Luminescent mechanism and devices attached thereto that illuminate any of the following spaces for safe and smooth } \\
\text { night activities: } \\
\text { (a) Roads defined in subparagraph } 1 \text { of article } 2 \text { of the road act } \\
\text { (b) Pedestrian walkways defined in subparagraph } 1 \text { of article } 2 \text { of the pedestrian safety and convenience enhancement ac } \\
\text { (c) Parks and green areas defined in subparagraph } 1 \text { of article } 2 \text { of the act on urban parks, green areas, etc. } \\
\text { (d) Other outdoor spaces designated by ordinance of the special metropolitan city, a metropolitan city, a special self } \\
\text { governing city, a do or the special self-governing province (hereinafter referred to as "City/Do") }\end{array}$} \\
\hline \multirow{4}{*}{$\begin{array}{l}\text { Enforcement rule of the act } \\
\text { on the prevention of light } \\
\text { pollution due to artificial } \\
\text { lighting [attached Table 1] }\end{array}$} & \multicolumn{8}{|c|}{$\begin{array}{l}\text { Acceptable standard of light emission(related Article } 6 \text { (1)) } \\
\text { 1. Light facilities of article } 2 \text { (1) }\end{array}$} \\
\hline & \multirow{2}{*}{ Standard ${ }^{\text {Classification }}$} & \multirow{2}{*}{ Applying hours } & \multirow{2}{*}{ Ref. value } & \multicolumn{4}{|c|}{ Lighting environment controlled zone } & \multirow{2}{*}{ Unit } \\
\hline & & & & A & B & C & $\mathrm{D}$ & \\
\hline & $\begin{array}{l}\text { Vertical plane of a } \\
\text { residential area }\end{array}$ & $\begin{array}{c}\text { from } 1 \mathrm{hr} \text { after sunset to } \\
1 \mathrm{hr} \text { before sunrise }\end{array}$ & Max. value & \multicolumn{3}{|c|}{ Under 10} & $\begin{array}{l}\text { Under } \\
25\end{array}$ & $\underset{\left(\mathrm{lm} / \mathrm{m}^{2}\right)}{\mathrm{lx}}$ \\
\hline
\end{tabular}


Table 4. Maximum values of vertical illuminance on properties

\begin{tabular}{c|c|c|c|c}
\hline Application conditions & $\mathrm{E} 1(\mathrm{~lx})$ & $\mathrm{E} 2(\mathrm{~lx})$ & $\mathrm{E} 3(\mathrm{~lx})$ & $\mathrm{E} 4(\mathrm{~lx})$ \\
\hline Pre-curfew & 2 & 5 & 10 & 25 \\
\hline Post-curfew & 0 & 1 & 2 & 5 \\
\hline
\end{tabular}

Source: Commission Internationale de l'Eclairage(2003)

장소로 국제조명위위원회는 도로와 공공의 이용이 있는 공간 에 대한 기준을 수립하고 있다. 해당 기준은 '도시공간의 조명 가이드(CIE 136:2000, Guide to the lighting of urban areas)' 로 적용 대상은 주거지역을 포함하여, 공공 커뮤니티 공간과 산업구역, 상업 중심구역에 이르는 장소의 모든 길을 포함한다. 단순히 조도에 대한 수치적인 기준뿐만 아니라, 공간 안에서 다가오는 사람에 대한 형상이나, 구조물과 눈부심을 포함한 색 재현, 그리고 조명기구의 미적인 측면까지 모두 복합적으로 고 려하고 있음을 알 수 있다.

또한 보행 공간에 대해서는 그 종류에 따라 빛 공해 측면에 서 Table 5 와 같은 기준을 제시하고 있다. 수평면 조도 $\left(\mathrm{E}_{\mathrm{H}}\right)$ 의 경우에는 보도를 따라 가장자리로부터 $5 \mathrm{~m}$ 의 범위에 해당하 는 값으로 일반적인 보도와 길에 적용할 수 있는 최소값과 최 대값을 제시하고 있으며, 기존의 수평면 조도 중심의 기준이 가지는 한계점을 감안하여 반원통형의 조도 $\left(\mathrm{E}_{\mathrm{SC}}\right)$ 에 대한 기준 을 제시하였다. 이는 곡면에 대한 조도 값인데, 높은 밀도의 열 린 보행공간의 상황 속에서 적용되는 기준으로 지나가는 사람 에 대한 인지 측면에 있어서 더 적합한 기준이다(Commission Internationale de l'Eclairage, 2000). 더불어 계단과 경사로의 경우, 수직면에 있어서는 연직면 조도에 대해, 디딤판에 있어서 는 수평면 조도 기준을 제시하였다. 이처럼 공간의 세부 특성 을 고려하여 그에 적합한 기준을 제시한 것을 확인할 수 있다.

Table 5. Lighting requirements for pedestrian

\begin{tabular}{|c|c|c|c|c|}
\hline \multicolumn{2}{|c|}{ Walkways \& paths } & $\mathrm{E}_{\mathrm{H}}$ ave(lx) & $\mathrm{E}_{\mathrm{H}} \min (\mathrm{lx})$ & $\mathrm{E}_{\mathrm{SC}} \min (\mathrm{lx})$ \\
\hline \multicolumn{2}{|c|}{ Parks in residential areas } & 5 & 2 & 2 \\
\hline \multicolumn{2}{|c|}{ City centre } & 10 & 5 & 3 \\
\hline \multicolumn{2}{|c|}{ Arcade and passageways } & 10 & 5 & 10 \\
\hline \multicolumn{2}{|c|}{ Staircases and ramps } & $\mathrm{E}_{\mathrm{H}}$ ave(lx) & $\mathrm{E}_{\mathrm{V}} \min (\mathrm{lx})$ & \\
\hline \multirow[t]{2}{*}{ Staircases } & (a) on risers & - & $>20$ & \\
\hline & (b) on treads & $>40$ & - & \\
\hline \multicolumn{2}{|c|}{ Ramps } & $>40$ & - & \\
\hline
\end{tabular}

Source: Commission Internationale de l'Eclairage(2000)

(2) 미국 IES(Illuminating Engineering Society) 와 IESNA (Illuminating Engineering Society North America)

미국의 IES는 도시공간을 포함한 외부공간에 대해 빛과 주 변의 관계성에 중점을 두고, 야간의 조명 환경에 따른 5 가지 외 부 조명환경 구역으로 구분하여(Table 6 참조) 해당 공간에서
이루어지는 활동의 정도에 따른 3 단계에 적합한 조도의 권장 기준을 제시하고 있다. 도시공원은 중간 정도의 활동에 해당하 는 공간으로 Table 7이 그 기준에 해당한다. 세부 내용을 살펴 보면, 수평면 조도와 함께 연직면에 대한 조도 기준을 제시하 고 있으며, 균제도(uniformity targets over area of coverage)까 지 다루고 있다. 특이한 점은 이용자의 연령에 따라 다른 조도 기준을 제시하고 있다는 것이다. 즉, 조명과 주변의 환경에 대 한 관계성은 물론이고, 이용자의 특성까지 중점을 둔 기준이 제시되고 있다.

북미조명공학회(IESNA)는 조명 디자인 사항에 대한 주요 쟁점을 제시하고, 이를 통해 기본적으로 설계 단계에서 고려해 야 할 사항을 지정하였다. 내용을 살펴보면, 공원과 광장, 보행 자 전용구역과 같은 공간에 대한 주요 디자인 쟁점 사항을 중 요한 정도에 따라 구분하였다(Table 8 참조). 조명기구나 공간 의 형태, 빛 분포에 비해 상대적으로 눈부심과 침입광 같은 빛 공해에 관련된 사항이나 색의 현시나 대조와 같은 조명계획을 통한 색 재현에 대한 부분을 더 중요한 디자인 요소로 다루고 있다. 또한 앞서 살펴본 국내의 수평면 조도 중심의 기준과는 다르게 수직면 조도가 더 중요한 디자인 사항이라고 설정하고 있다.

Table 6. Nighttime outdoor lighting zone definitions

\begin{tabular}{c|l}
\hline Zone & \multicolumn{1}{c}{ DZfinition } \\
\hline $\begin{array}{c}\text { High ambient lighting } \\
\text { LZ3 }\end{array}$ & $\begin{array}{l}\text { Areas of human activity where the vision } \\
\text { of human residents and users is adapted to } \\
\text { high light levels }\end{array}$ \\
\hline $\begin{array}{c}\text { Moderately high ambient } \\
\text { lighting }\end{array}$ & $\begin{array}{l}\text { Areas of human activity where the vision } \\
\text { of human residents and users is adapted to } \\
\text { moderately high light levels }\end{array}$ \\
\hline $\begin{array}{c}\text { LZ2 } \\
\text { lighting }\end{array}$ & $\begin{array}{l}\text { Areas of human activity where the vision } \\
\text { of human residents and users is adapted to } \\
\text { moderate light levels. }\end{array}$ \\
\hline $\begin{array}{c}\text { LZ1 } \\
\text { Low ambient lighting }\end{array}$ & $\begin{array}{l}\text { Areas where lighting might adversely af- } \\
\text { fect flora and fauna or disturb the charac- } \\
\text { ter of the area }\end{array}$ \\
\hline No ambient lighting & $\begin{array}{l}\text { Areas where the natural environment will } \\
\text { be seriously and adversely affected by } \\
\text { lighting. }\end{array}$ \\
\hline
\end{tabular}

Source: DiLaura(2011)

(3) 일본산업규격 JIS(Japanese Industrial Standards) 한국산업규격의 조도 기준이 참조한 일본 국가규격인 JIS Z 9110 규정은 조명 설계기준의 일반 원칙을 세 가지로 제시하고 있다(Table 9 참조). 해당 내용을 살펴보면, 단순히 밝기에 초 점을 맞춘 것이 아니라, 이용자와의 관계성을 고려하여 계획하 는 것을 강조하고 있다. 더불어 에너지의 이용 측면과 함께 주 변 환경과의 조화를 고려하고 있다. 조명의 특성 또한, 조도에 
Table 7. Pedestrian ramps, stairs, steps

\begin{tabular}{|c|c|c|c|c|c|c|c|c|c|c|c|}
\hline \multirow{4}{*}{$\begin{array}{c}\text { Intensity of } \\
\text { activity }\end{array}$} & \multirow{4}{*}{ Zone } & \multicolumn{8}{|c|}{ Recommended maintained illuminance targets (lux) } & \multirow{2}{*}{\multicolumn{2}{|c|}{$\begin{array}{l}\text { Uniformity targets over area of } \\
\text { coverage }\end{array}$}} \\
\hline & & \multicolumn{4}{|c|}{ Horizontal targets $\left(\mathrm{E}_{\mathrm{H}}\right)$} & \multicolumn{4}{|c|}{ Vertical targets $\left(\mathrm{E}_{\mathrm{V}}\right)$} & & \\
\hline & & \multicolumn{4}{|c|}{ Visual ages of observers where at least half ${ }^{3)}$} & \multicolumn{4}{|c|}{ Visual ages of observers where at least half } & \multicolumn{2}{|c|}{$\begin{array}{l}\text { If different uniformities apply } \\
\qquad\left(E_{\mathrm{H}}: E_{V}\right)\end{array}$} \\
\hline & & & $<25$ & $25 \sim 65$ & $>65$ & & $<25$ & $25 \sim 65$ & $>65$ & Min:Ave & Ave:Min \\
\hline \multirow{5}{*}{ Medium } & LZ4 & E & 4 & 8 & 16 & $\mathrm{C}$ & 2 & 4 & 8 & $4: 1$ & $5: 1$ \\
\hline & LZ3 & $\mathrm{D}$ & 3 & 6 & 12 & B & 1 & 2 & 4 & $4: 1$ & $\begin{array}{c}5: 1 \\
(10: 1)\end{array}$ \\
\hline & LZ2 & $\mathrm{C}$ & 2 & 4 & 8 & B & 1 & 2 & 4 & $4: 1$ & $\begin{array}{c}5: 1 \\
(10: 1)\end{array}$ \\
\hline & LZ1 & B & 1 & 1 & 2 & A & 0.5 & 1 & 2 & $4: 1$ & $\begin{array}{c}5: 1 \\
(10: 1)\end{array}$ \\
\hline & LZ0 & A & 0.5 & 1 & 2 & - & 0 & 0 & 0 & $4: 1$ & \\
\hline
\end{tabular}

Source: DiLaura(2011)

Table 8. Design issues: Parks, plazas and pedestrian malls

\begin{tabular}{|c|c|c|c|}
\hline Design issues & & Design issues & \\
\hline $\begin{array}{c}\text { Appearance of space \& } \\
\text { luminaires }\end{array}$ & (a) & Source/task/eye geometry & ○ \\
\hline $\begin{array}{l}\text { Color appearance } \\
\text { (\& color contrast) }\end{array}$ & - & \multirow{2}{*}{$\begin{array}{c}\text { Sparkle/desirable reflected } \\
\text { highlights }\end{array}$} & \multirow[t]{2}{*}{$x$} \\
\hline Direct glare & - & & \\
\hline Light distribution on surfaces & () & Surface characteristics & () \\
\hline Light distribution on surfaces & - & Special considerations & $x$ \\
\hline Modelling of faces or objects & $\bullet$ & Notes on special considerations & $x$ \\
\hline Peripheral detection & - & Illuminance(horizontal) & (2) \\
\hline Point(s) of interest & () & Shadows & 0 \\
\hline Reflected glare & - & Illuminance(vertical) & 0 \\
\hline
\end{tabular}

0: Very important, (): Important, (): Somewhat important, X: Not important or not applicable

Source: DiLaura(2011)

Table 9. General principles of lighting design

\footnotetext{
To offer good light conditions, we should consider following articles;

a) Proper light conditions for purpose of activity

b) Energy efficiency

c) Harmony with surroundings
}

Especially when you are about to set light conditions, it is important to fulfill all conditions such as illuminance and its distribution, brightness, luminance, shades, color, and color rendering.

Source: Japanese Standards Association(2010)

국한된 것이 아니라, 조도나 휘도 분포, 빛의 색상, 음영, 연색 성 등과 같은 다양한 요소를 다루어야함을 강조하고 있다.

Table 10은 길, 광장, 그리고 공원에 적용될 수 있는 교통량 에 따른 기준이다. 특히 위험 요소가 있을 경우, 그 정도에 따 라 별도의 기준을 마련해놓고 있다는 사실 역시 주목할 만하다.
Table 10. Standards for path, plaza and park

\begin{tabular}{|c|c|c|c|c|c|c|}
\hline \multicolumn{3}{|c|}{$\begin{array}{c}\text { Type } \\
\text { (territory, work or activity) }\end{array}$} & \multirow{2}{*}{$\begin{array}{c}\begin{array}{c}\text { Illuminance } \\
\overline{\mathrm{E}} \mathrm{m}(\mathrm{lx})\end{array} \\
20\end{array}$} & \multirow{2}{*}{$\begin{array}{c}\begin{array}{c}\text { Uniformity } \\
\text { of }\end{array} \\
\text { illuminance } \\
\text { Uo }\end{array}$} & \multirow{2}{*}{$\begin{array}{c}\text { Outdoor } \\
\text { lighting } \\
\text { limit } \\
\mathrm{GR}_{\mathrm{L}} \\
50\end{array}$} & \multirow{2}{*}{$\begin{array}{c}\begin{array}{c}\text { Color } \\
\text { renderign } \\
\mathrm{Ra}\end{array} \\
20\end{array}$} \\
\hline \multirow{3}{*}{$\begin{array}{c}\text { Pedestrian } \\
\text { traffic }\end{array}$} & \multirow{3}{*}{ Outdoor } & High & & & & \\
\hline & & Medium & 10 & - & 50 & 20 \\
\hline & & Low & 5 & - & 55 & 20 \\
\hline \multirow{3}{*}{$\begin{array}{c}\text { Traffic in } \\
\text { plaza }\end{array}$} & \multicolumn{2}{|c|}{ High } & 50 & - & 50 & 20 \\
\hline & \multicolumn{2}{|c|}{ Medium } & 30 & - & 50 & 20 \\
\hline & \multicolumn{2}{|c|}{ Low } & 15 & - & 55 & 20 \\
\hline \multirow{4}{*}{ Risk level } & \multicolumn{2}{|c|}{ High } & 50 & - & 45 & 20 \\
\hline & \multicolumn{2}{|c|}{ Medium } & 20 & - & 50 & 20 \\
\hline & \multicolumn{2}{|c|}{ Low } & 10 & - & 50 & - \\
\hline & \multicolumn{2}{|c|}{ Very low } & 5 & - & 55 & - \\
\hline
\end{tabular}

Source: Japanese Standards Association(2010)

\section{3. 소결}

야간경관과 경관조명에 대한 정의에 기반하여 도시공원은 주간뿐만 아니라, 야간에도 해당 공간과 이용자의 특성, 인접 지역과의 관계성을 고려하여 안전, 쾌적성, 심미성 차원에서 빛 을 통합적으로 다루어야 한다는 점을 발견하였다. 이러한 측면 은 해외의 가이드라인에서 세부 지침과 규정으로 구체화되는 반면, 우리나라 관련 제도는 그 규제 대상과 항목의 구체성과 다양성이 현저히 떨어지는 것으로 나타났다.

국내 관련 규정에 비해 해외 지침에 나타나는 차별화된 측면 은 다음과 같다. 첫째, 조명 디자인에 대한 전반적인 디자인 이 슈와 원칙을 제시되고 있으며, 둘째, 이용자(혹은 관찰자) 관점 에서 물체나 다가오는 대상에 대한 식별성과 시인성을 강조하 고, 이용자의 특성이나 보행량과 활동의 위험 정도에 따른 기 준이 제시된다. 셋째, 수평면 조도의 한계점을 보완하는 연직면 
조도나 균제도, 반원통형 조도, 연색성 등 빛을 규정하는 다른 항목의 지침을 함께 제시하고 있으며, 마지막으로 적용 공간을 세분화하여 공간별 특징에 맞는 세부 지침을 규정하고 있다는 점이다.

반면, 한국산업규격인 $\mathrm{KS}$ 의 공원 관련 기준은 수평면 조도 를 포괄적으로만 다루고 있어 전반적인 조명환경을 계획하거나 평가하기에는 명백한 한계가 있다.

\section{III. 연구 방법}

서울시 도시공원의 야간경관의 실태를 분석하기 위한 연구 방법은 Figure 1과 같다. 첫째, 전문가 면담을 통해 일반적인 도시공원의 야간경관에 대한 인식과 그 수행 방식을 파악하였 다. 둘째, 대상지를 선정하여 조성계획 당시의 도면과 준공도면 을 비교하고, 현재 조명기구 설치 현황과 조도를 측정하여 도 면과 비교 검토하였다.

\begin{tabular}{|c|}
\hline \multicolumn{2}{|c|}{ Interview with professionals } \\
\hline Field survey \\
\hline Case study \\
Discussion and conclusion \\
\hline
\end{tabular}

Figure 1. Study process

\section{1. 전문가 면담 개요}

도시공원의 야간경관과 관련하여 계획 및 시공을 포함한 전 반적인 조성 과정에 있어서 절차적인 쟁점을 파악하고자 관련 전문가를 대상으로 면담조사를 실시하였다. 면담 조사기간은 2017년 10월로 총 6명을 대상으로 이루어졌으며, 현재 조경과 조명 부문이 개별적으로 진행되는 점을 감안하여, 크게 조경전 문가와 조명전문가 두 분야로 나누어 진행하였다. 조경의 경우, 도시공원 조성 프로세스 내에서 계획 및 설계와 시공 분야가 수행하는 역할이 서로 다르므로 이를 기준으로 두 가지로 나누 었다. 면담은 반구조화된 인터뷰 방식으로 주요 논의 주제를 네 가지로 제시하였으나, 자유롭게 의견을 개진하도록 하였다. 인터뷰 시간은 최소 30 분에서 1 시간 정도로 이루어졌다. 계획 및 설계 분야의 경우에는 경력 10 년 이상의 경력자를 대상으로 하였으며, 시공 분야의 경우에는 5 년 이상의 현장 책임자를 대 상으로 하였다. 면담의 주요 논의 주제는 Table 11 과 같다.

\section{2. 사례 연구}

1) 대상지 선정
Table 11. Main issues of interview with professionals

\begin{tabular}{l|l}
\hline & \multicolumn{1}{|c}{ Issues } \\
\hline A & $\begin{array}{l}\text { Degree of perception and reflection about nightscape of park } \\
\text { through the whole making process }\end{array}$ \\
\hline B & Mainly considered nightscape factor in planning process of park \\
\hline C & Needs and cooperating process in planning or constructing phase \\
\hline D & $\begin{array}{l}\text { Current issues and problems of park lighting plan and constru- } \\
\text { ction }\end{array}$ \\
\hline
\end{tabular}

도시공원을 대상으로 조명기구의 설치 현황을 분석하기 위 해, Table 12 와 같은 선정 기준을 설정하여 서울시 여의도공원 을 대상지로 선정하였다.

여의도공원은 여의도광장 공원화 사업을 통해 1999년 7월 준공 이후 약 20 여 년의 이용 기간을 가진 공원으로, 이에 따른 부분적 노후화가 있을 것으로 예상되었다. 노후화와 더불어 수 목의 생장으로 인한 울폐도 증가에 따라 초기 조명계획에 영향 을 미칠 가능성이 높다고 판단되었다. 또한, 도시지역권이라는 일정 규모 이상의 공원으로 비교적 다양한 행태가 이루어질 것 으로 예상이 된다.

\section{2) 현장 조사 방법}

도시공원 야간경관 실태는 조명기구의 구성에 대한 분석과 조명의 물리량 측정의 두 가지 방법으로 진행하였다. 조명 기 구의 구성은 크게 광원과 조명 방식, 배광 형태로 구분하였다. 조명의 물리량은 크게 조도와 색온도로 나누어 조사하였으며, 수평면 조도는 KS C 7612의 측정 방법에 따라, Konica Minolta $\mathrm{T}-10$ 을 측정 도구로 이용하였으며, 색온도는 CL-200을 이용 하여 측정하였다. Figure 2 는 공간별 조도 측정 방법을 나타내 며, 수평면 조도의 측정 점은 바닥면 위 $15 \mathrm{~cm}$ 이하로 정하 고, 공간의 크기나 산책로의 경우 폭에 따라 측정 점의 간격을 달리하였다.

\section{IV. 도시공원의 야간경관}

\section{1. 전문가 면담을 통한 쟁점 분석}

각 분야의 전문가들은 공통적으로 공원을 포함한 도시의 야 Table 12. Criteria for site selection

\begin{tabular}{l}
\hline Standard of site-selection \\
\hline Urban park which does not have any restricts in service hours \\
\hline Urban park which was built before more than 20 years \\
\hline Urban park with size of more than hundred thousand square meter \\
\hline Urban park with different land-use nearby showing different use \\
pattern of day and night time \\
\hline Urban park that has an archive of design documents \\
\hline
\end{tabular}




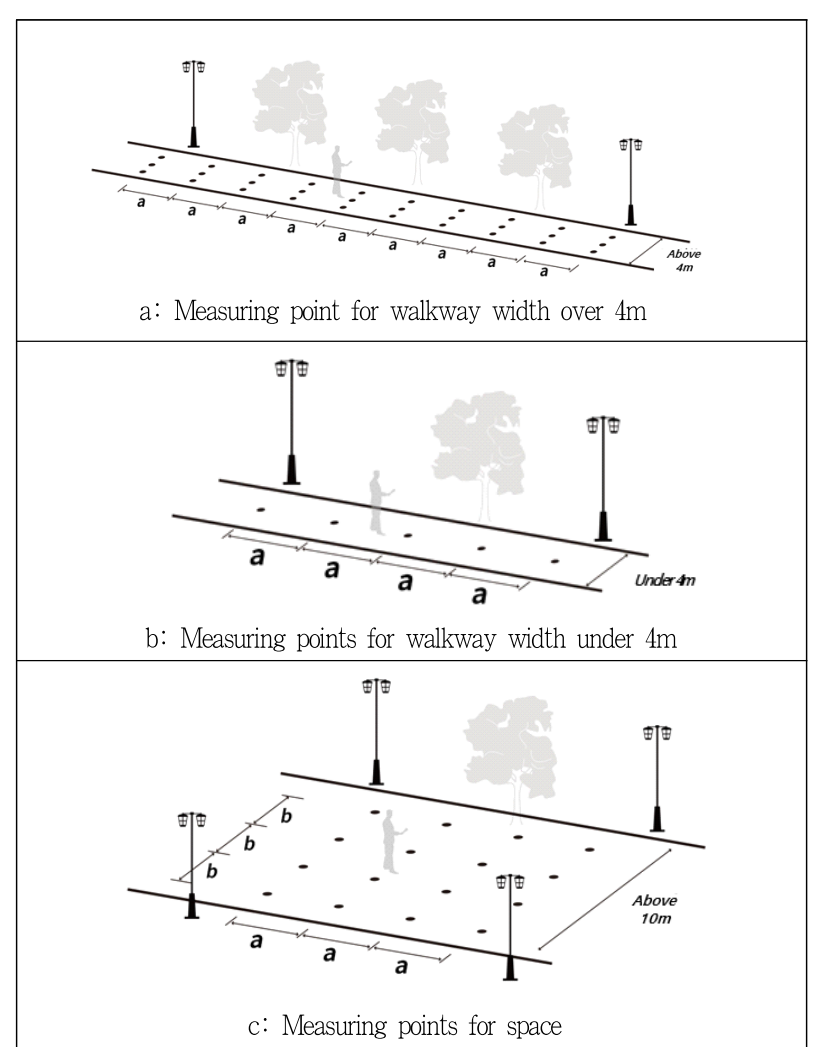

Figure 2. Measurement method

간경관이 이전보다 훨씬 더 중요해지고 있다는 사실에 공감하 였다. 일반적으로 조경계획 · 설계 과정에 있어 기본계획도서나 인 · 허가도서에서는 야간경관을 본격적으로 다루지 않고, 실시 설계 단계에서 발주처의 요구에 의해 진행되는 관행이 이어져 왔다고 볼 수 있다. 하지만 공원의 경우, 최근 각종 심의에서 야 간경관이나 야간의 안전을 중요하게 생각하는 경우가 많아, 초 기 설계 단계부터 야간경관을 반영하려는 경향이 생기고 있다 는 사실이 확인되었다. 다만, 아직까지는 안전에 더 많은 비중 을 두고 있어, 경관연출과 관련한 사항들은 상대적으로 부족하 다. 또한, 설계과정에서 조명은 조경 계획분야와는 별도로 다루 어지는데, 경관조명 특화설계를 포함한 대체적인 조명계획은 조명관련 전문 업체에 외주를 주는 방식으로 진행되고 있는 것이 보편적이다.

조경 시공관련 전문가 면담 결과, 야간의 안전이나 빛공해 관 련 사항을 포함한 경관계획 내용은 실시설계도면이 심의를 거 쳐 현장에 제공되기 때문에 현장 관리자가 별도로 고려할 사항 은 아닌 것으로 파악되었다. 경관적인 측면에서 시공 관리자에 의한 설계변경이 일부 진행되기도 하지만, 이 역시 발주를 직 접 진행하는 경우에만 드물게 이루어지는 것으로 확인되었다. 일반적인 경우, 설비업체가 단기간의 공정을 목표로 도면이 지 시하는 사항을 수동적으로 수행하고 있다고 볼 수 있다.

조명 및 경관계획 전문가는 경관조명계획이 후순위의 공정
으로 진행되는 현 프로세스 자체에 대해 문제를 제기하였다. 이러한 현상은 경관조명에 대한 발주처의 인식이 부족한 것이 원인일 수 있고, 결국 경제성에 집중하는 조명 설비업자에게 공사가 넘겨지는 결과를 초래한다. 전문가들은 조명계획이 공 원 계획 초기에 통합적으로 다뤄져야한다고 강조하였다.

\section{2. 사례 연구}

\section{1) 계획 및 관련 도서}

여의도공원 야간경관의 계획 개념과 의도를 파악하기 위해 기본계획도서인 여의도광장의 공원화 사업 기본 및 실시설계 서(1997)를 검토하고, 이후 공구별 준공도를 참고하여 파악한 내용은 다음과 같다.

기본계획도서에 조명계획은 조경이 아닌 전기부문 전기설비 계획에 포함되어 있으며, Table 13과 같은 전기설비 기본방향 을 토대로 계획되었다. 기본방향을 살펴보면 주로 설치의 편의 성과 경제성, 관리의 용이성 측면에서 기본 방향이 이루어졌음 을 알 수 있다.

전기설비계획 중 조명 부분을 살펴보면, 여의도공원을 크게 6 가지 공간(자연생태의 숲, 그늘아래 문화의 마당, 구릉형 잔디 마당, 한국전통의 숲, 자전거도로 및 산책로)으로 구분하여 세 부 공간별 연출기법과 가로등의 형태를 제시하고 있다. 자세 한 내용은 Table 15 와 같다. 또한 Table 14 와 같이 공원 내 공 간별로 조도기준과 그에 따르는 조명기구의 설치 유형을 제안 하였다.

계획도서를 살펴본 결과, 별도로 조명계획의 내용은 존재하 였으나, 지침 수준의 연출기법과 개별 조명기구에 대한 단편적 예시에 그쳤다. 또한, 자전거도로와 산책로를 동일한 조명기구 로 계획한 것과 공원 전반에 걸쳐서 메탈할라이드 등이 일괄 적으로 설치된 점을 볼 때, 공간의 이용 특성을 면밀히 고려하 지 않았다는 사실을 파악할 수 있다. 이러한 점은 기본방향에 서 확인할 수 있듯이, 계획 단계에서는 매우 개략적인 수준으 로만 결정하고, 이후 조성 과정에서 설치 및 관리상의 편의성 에 중점을 두고 조성한 결과가 현재에 이르고 있다는 점을 알

Table 13. Basic direction of lighting plan in Yeouido Park

\begin{tabular}{c|c}
\hline Standard & Content \\
\hline Safety & $\begin{array}{c}\text { Invulnerable to human body and equipment } \\
\text { protection }\end{array}$ \\
\hline Efficiency & $\begin{array}{c}\text { Saving energy and application of up-to-date } \\
\text { technology }\end{array}$ \\
\hline Management & Simple and handy system arrangement \\
\hline Economic feasibility & Considering operating expenses and durability \\
\hline Reliability & Equipment with low rate of malfunction \\
\hline Decorativeness & \begin{tabular}{c} 
Shape being harmonious with architectural space \\
\hline Responsiveness
\end{tabular} \\
\hline
\end{tabular}


Table 14. Proposed illuminance and installation method of Yeouido Park

\begin{tabular}{|c|c|c|c|c|}
\hline Area List & $\begin{array}{l}\text { Intensity of } \\
\text { illuminance(lx) }\end{array}$ & $\begin{array}{l}\text { Lamp } \\
\text { type }\end{array}$ & Type & Function \\
\hline Park & $15 \sim 30$ & $\mathrm{MH}$ & POLE & \multirow{4}{*}{$\begin{array}{c}\text { Landscape } \\
\text { light }\end{array}$} \\
\hline Bike road & 30 & $\mathrm{MH}$ & POLE & \\
\hline Walk & 30 & $\mathrm{MH}$ & POLE & \\
\hline Cultural yard & 30 & $\mathrm{MH}$ & POLE & \\
\hline $\begin{array}{c}\text { Pond } \\
\text { grass yard }\end{array}$ & $5 \sim 15$ & $\mathrm{MH} / \mathrm{L}$ & $\begin{array}{l}\text { POLE, } \\
\text { On the } \\
\text { floor }\end{array}$ & $\begin{array}{l}\text { Landscape } \\
\text { light, } \\
\text { penetrating } \\
\text { light }\end{array}$ \\
\hline
\end{tabular}

Table 15. Proposed spatial lighting guides of Yeouido park

\begin{tabular}{|c|c|c|}
\hline Area & Spatial lighting method & Shape of lights \\
\hline $\begin{array}{l}\text { Eco } \\
\text { forest }\end{array}$ & $\begin{array}{l}\text { - Eco-friendly and being harmonious } \\
\text { with nature } \\
\text { - Considering the beauty of nature and } \\
\text { activity of birds }\end{array}$ & \\
\hline $\begin{array}{l}\text { Cultural } \\
\text { yard }\end{array}$ & $\begin{array}{l}\text { - Applying to space with "up-light" } \\
\text { lighting method } \\
\text { - Lighting plan with bright and lively } \\
\text { - Creating more active spatial lighting } \\
\text { plan with festival and recreation pro- } \\
\text { gram targeting the younger generation }\end{array}$ & \\
\hline $\begin{array}{l}\text { Green } \\
\text { yard }\end{array}$ & $\begin{array}{l}\text { - Area where has spatial contrast with } \\
\text { grass and high trees } \\
\text { - Mainly focus on harmonious light } \\
\text { effect with grass and trees } \\
\text { - Use "up-light" methods together for } \\
\text { presenting a beauty of trees }\end{array}$ & (6.8) \\
\hline $\begin{array}{l}\text { Korean } \\
\text { traditional } \\
\text { forest }\end{array}$ & $\begin{array}{l}\text { - Area with natural and comfort at- } \\
\text { mosphere } \\
\text { - Lighting plan mainly focus on Korean } \\
\text { traditional feelings }\end{array}$ & ? \\
\hline $\begin{array}{l}\text { Bike } \\
\text { way }\end{array}$ & $\begin{array}{l}\text { - Circling roads throughout park and } \\
\text { it could be showing whole sizeand } \\
\text { range of park } \\
\text { - Applying lights which has bright } \\
\text { and clear conditions } \\
\text { - Mainly consider safety between bike } \\
\text { riders and pedestrians }\end{array}$ & 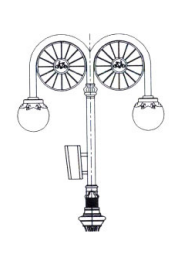 \\
\hline $\begin{array}{l}\text { Pedestrian } \\
\text { path }\end{array}$ & $\begin{array}{l}\text { Providing people with comfort and } \\
\text { calm feelings } \\
\text { - Lighting plan providing with atmos- } \\
\text { phere that makes nature and human } \\
\text { together }\end{array}$ & (I) \\
\hline
\end{tabular}

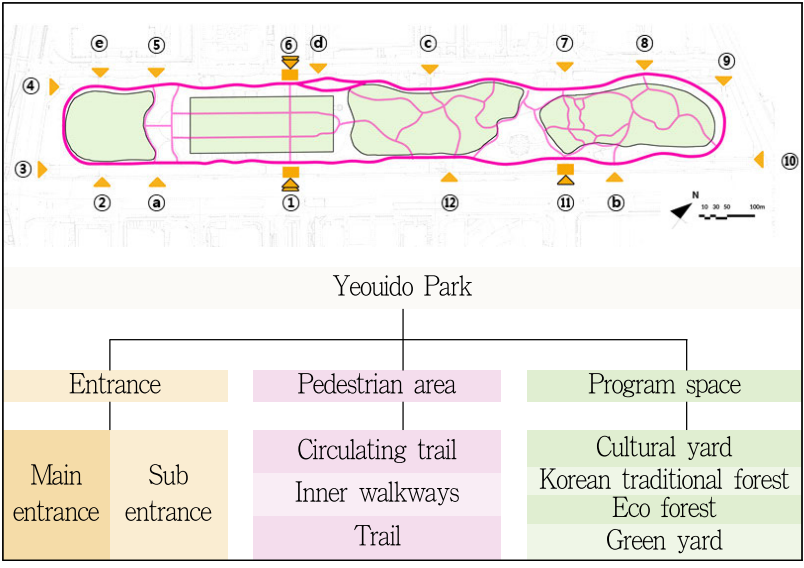

Figure 3. Space classification system of Yeouido Park

수 있다.

\section{2) 현장 조사}

현장 조사 기간은 2017년 10월 11일에서 10월 13일까지, 11 월 14 일에서 11 월 16 일까지 총 6 일간 이루어졌고, 20시에서 25시 사이에 진행되었다. 조명기구의 설치 현황은 준공도면을 중심으로 현장 조사 결과와 비교·검토하였다. 한국산업규격 (KS A 3011)에 명시되어 있는 수평면 조도 기준을 우선적으 로 조사하였으며, 공원의 야간경관 연출 효과를 파악하고자 색온도와 함께 배광제어 방식을 조사하였다.

(1) 조도 분포 및 기준 확보

\section{(1) 주 출입구}

한국 산업 규격(KS A 3011)과 서울시 도시공원 경관조명 기준 및 지침에 의하면 도시공원의 경관조명계획에 있어서 기 준 조도 유지를 통한 공적 공간에서 시인성과 안전성 확보가 가 장 기본이라 할 수 있다. 이를 위해서 공원 내 공간별로 수평면 조도 $\left(\mathrm{E}_{\mathrm{H}}\right)$ 를 측정하였으며, 그 내용은 다음 Table 16과 같다.

여의도공원의 주 출입구는 총 12 개소로 현재 공사가 진행 중 인 출입구 1 개소를 제외한 11 곳을 측정하였다(Figure 3 참조). 그 결과, 주 출입구 4 개소(2), (4), (9), (10)는 수평면 조도의 평 균값이 KS A 3011 조도 기준의 최저인 $6 \mathrm{~lx}$ 에 미치지 못하였 다. 더불어 3 개소(8, (11), (12)의 경우에는 최저 기준을 상회하 는 수준이었다.

주 출입구 (1)과 (6)은 남북으로 국회의사당역, 여의도역으 로 이어지며, 야간의 주요 이용공간인 문화의 마당으로 직접 연결되어 이용자의 통행량이 가장 높은 주 출입구임에도 불 구하고, 각각 $13.35 \mathrm{~lx}, 9.76 \mathrm{~lx}$ 로 KS A 3011에 명시된 '공원의 주된 장소' 기준에 미치지 못하는 것으로 측정되었다. 연직면 조도의 경우, 주 출입구 (1)은 상대적으로 높은 측정값으로 확 
Table 16. Measured value of illuminance in Yeouido Park

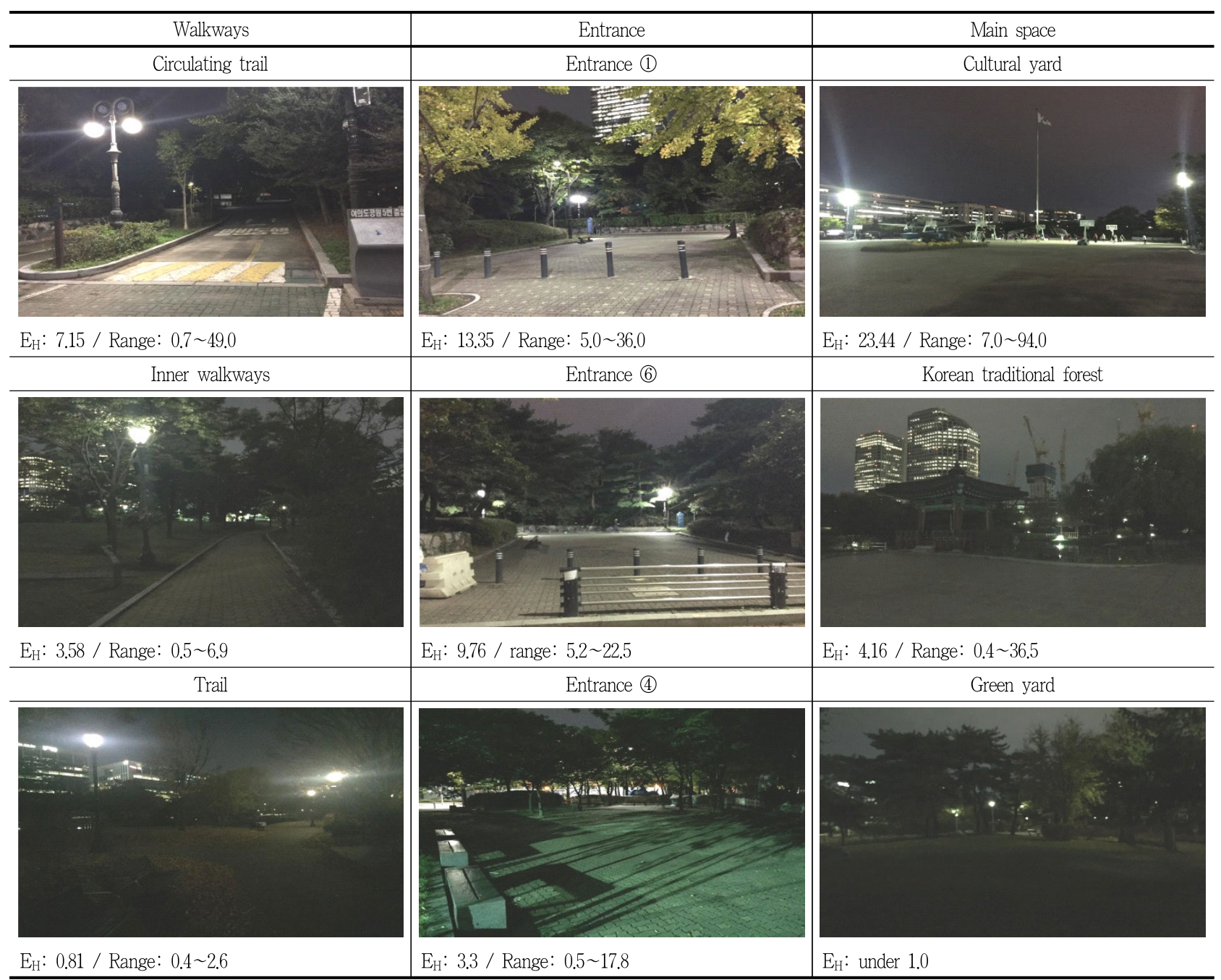

$\mathrm{E}_{\mathrm{H}}$ : Horizontal illuminance, Unit: $\mathrm{lx}$

인되었는데, 이는 공간의 규모를 고려하지 않고 동일한 개수의 조명기구를 배치하였기 때문인 것으로 판단된다.

\section{(2) 동선}

여의도공원의 동선체계는 크게 순환동선, 공원 내 세부동선 과 이를 연결해주는 보조동선으로 이루어져 있으며, 순환동선 은 보행로와 자전거 도로가 나란히 조성되어 있다. 조사는 공 원을 둘러싼 외곽의 경계까지 포함하여 진행되었다.

주 동선의 수평면 조도 측정값은 $7.15 \mathrm{~lx}$ 로 최저 기준은 넘었 으나, 보조 동선이나 세부 동선은 최저 기준에 한참 못 미치는 것으로 나타났다. 여의도공원의 주 동선은 자전거도로와 나란 히 배치되어 공원 전체를 순환하는 형태로, 지역 주민이나 직 장인들이 자전거를 타거나 달리기와 산책을 하는 공간임을 감 안한다면 자전거도로와 주 동선의 구분 없이 동일한 조도를 확 보한 것은 길의 특성을 반영하지 않은 것이라 볼 수 있다. 보조
동선과 세부 동선에서는 공원 내부로 들어갈수록 조도 측정값 은 확연히 낮아져, 주변 사람의 얼굴조차 육안으로 확인할 수 없을 정도였다.

\section{(3) 세부 공간}

세부 공간별로 조도를 측정한 결과, 야간 스포츠 활동이 일 어나는 공간인 문화의 마당을 제외한 공원 내 대부분 공간의 측정값이 최저 기준에 미치는 못하는 것으로 확인되었다.

조명등 설치가 조도 기준에 맞추어 진행되었음에도 불구하 고, 실제로는 기준 조도에도 못 미치는 공간이 대부분이었으 며, 이는 공원 내 수목의 변화와 같은 조명 이외의 요소에 대해 충분히 고려하지 않았거나, 변화에 능동적으로 대처하지 못했 음을 증명한다. 조도의 분포 역시 균질하지 않아 기준치에 부 합하는 조도가 측정된 장소라도 해당 공간은 전반적으로 어두 웠다. 
Table 17. Detailed specification of lighting equipment in Yeouido Park

\begin{tabular}{|c|c|c|c|c|}
\hline Area & Specification $(W)$ & Light source & Type & Qty. \\
\hline Outer area & MHL 2/250 & \multirow{5}{*}{$\begin{array}{l}\text { Metal } \\
\text { haloid } \\
\text { lamp }\end{array}$} & Pole $(7.29 \mathrm{~m})$ & 58 \\
\hline Bike roads & MHL 2/250 & & $\operatorname{Pole}(5 \mathrm{~m})$ & 82 \\
\hline $\begin{array}{c}\text { Korean traditional } \\
\text { forest }\end{array}$ & MHL 1/250 & & Pole(5.64 m) & 27 \\
\hline Walkways & MHL 1/175 & & Pole $(4.75 \mathrm{~m})$ & 75 \\
\hline $\begin{array}{l}\text { Samo-pavilion } \\
\text { eco forest }\end{array}$ & MHL 1/175 & & Pole $(5.24 \mathrm{~m})$ & 25 \\
\hline Palgak-pavilion & HQI 1/150 & $\begin{array}{l}\text { Metal haloid } \\
\text { lamp(Pocket) }\end{array}$ & Floodlight & 7 \\
\hline $\begin{array}{c}\text { Cultural yard } \\
\text { under the shadow }\end{array}$ & $\begin{array}{c}\text { MHL } 8 / 400 \\
\text { NA } 3 / 400\end{array}$ & $\begin{array}{l}\text { Metal haloid lamp, } \\
\text { high tension } \\
\text { sodium lamp }\end{array}$ & $\begin{array}{c}\text { Floodlight } \\
\text { tower } \\
(13.5 \mathrm{~m})\end{array}$ & 6 \\
\hline Pond & IL $1 / 100$ & Incandescent lamp & Floodlight & 28 \\
\hline Up-light for trees & PAR-56 300 & Halogen & Bollard & 11 \\
\hline
\end{tabular}

\section{(2) 색온도 ${ }^{4)}$ 측정}

현장 조사 결과, 공원 전반에 걸쳐 색온도는 $5,000 ~ 6,000 \mathrm{~K}$ 로 측정되었는데. 이는 광원의 대다수가 메탈할라이드 램프이 기 때문이다. 획일적인 등기구로 인해 전반적으로 공원의 분위 기를 차가운 느낌으로 만드는 주요 원인이라고 할 수 있다.

\section{(3) 조명기구의 구성}

조명기구의 구성 요소는 크게 광원의 종류, 조명방식, 기구 형태로 나누어 조사하였다. 공구별 준공도와 현장 조사를 통해 다음 Table 17 과 같은 여의도공원 전체의 조명 현황을 확인하 였다.

백열전구를 사용한 연못을 제외하고 공원 외곽과 자전거도 로 등 공원 전반에 걸쳐 대부분의 등기구가 메탈할라이드로 이 루어져 있다는 점은 공간별로 밝기 차이만 두었을 뿐 공간별 조명 연출은 세심하게 고려하지 않았다는 사실을 보여준다.

\section{(4) 기구 형태 및 배광 방식}

공원 내 조명기구는 총 10 가지로 계획되었다(Table 18 참 조). 조성계획에서 제시된 조명 기구는 형태만 보았을 때는 충 실히 이행된 것으로 보이지만, 별도의 컷오프가 적용되지 않고 등기구의 높이에만 차이를 둔 것으로 보아, 개별 등기구의 배 광 방식에 대해 특별히 고려하지 않았다고 볼 수 있다.

\section{3) 현장 조사 종합}

도시공원의 야간경관 실태 분석을 위해 진행한 현장 조사 결 과는 다음과 같다.

수평면 조도 측정 결과, 공원 전반에 걸쳐 수평면 조도는 고 르지 못하며, 측정값 또한 평균적으로 최저 기준 이하로 확인 되었다. 계획도서에 제시된 조도 기준은 모든 세부 공간에서
Table 18. Present light fixtures in Yeouido Park

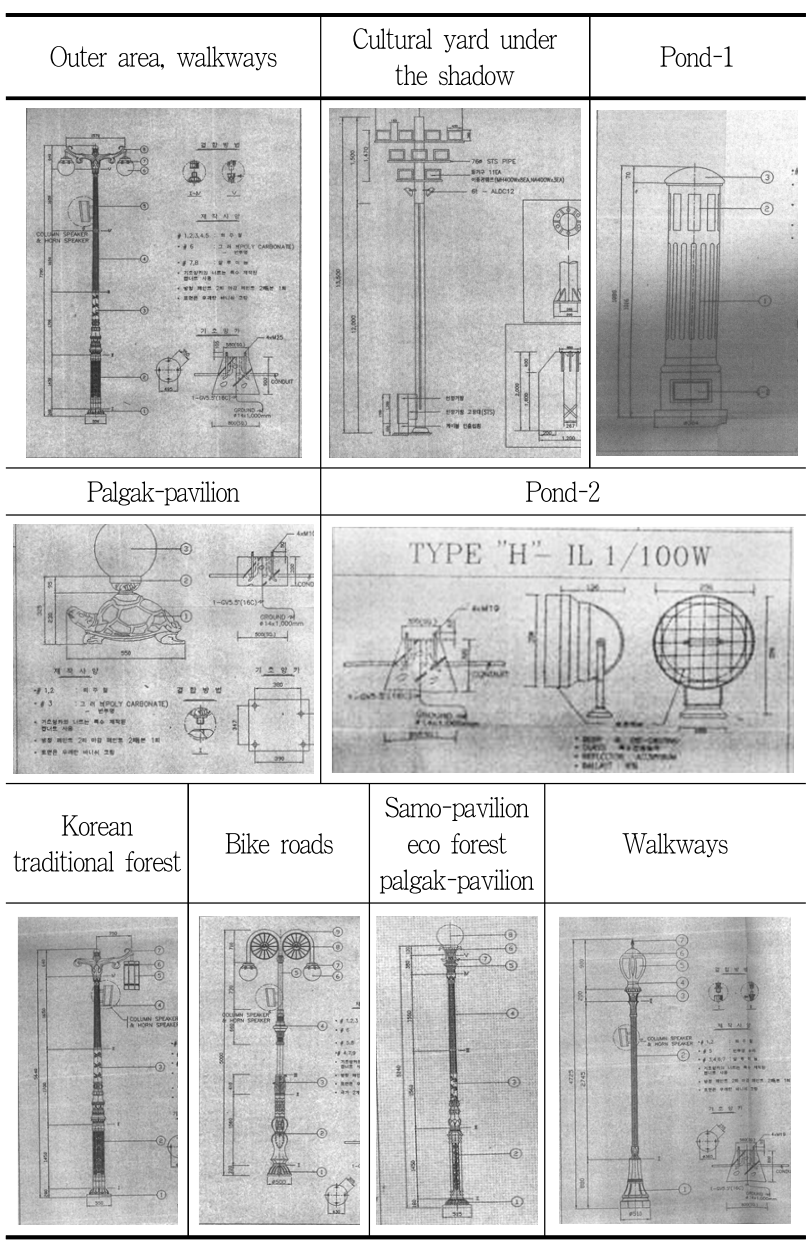

Source: Management Office of Yeouido Park(1999)

충족되지 못한 것으로 확인되었다. 주 출입구보다 부출입구의 조도 측정값이 더 높은 것으로 측정되었는데, 이는 부출입구의 다수가 업무지구와 면해 있는 공원 북쪽에 위치하여 외부 조명 에 의한 영향이 크기 때문이다. 평행하게 조성된 자전거도로 와 산책로는 야간 이용이 많은 순환형 운동공간임에도 불구하 고, 이용 방식의 차이에 상관없이 최저 기준에 맞추어져 있는 것으로 확인되었다. 공간별로는 주요 운동공간인 문화의 마당 을 제외하고는 전반적으로 조도의 측정값이 최저 기준 수준이 거나 그 이하인 것으로 파악되었다.

조도 중심의 안전성 확보 이외에도 연출 측면을 분석하기 위 해 색온도와 배광 제어 측면을 조사·분석하였다.

광원의 경우에는 연못을 제외한 공원 전반에 걸쳐서 메탈할 라이드 등기구가 설치되어 결과적으로 동일한 색온도로 인한 차가운 느낌의 야간 경관을 초래하였다. 더불어 배광 제어를 고려하지 않았던 것으로 파악되었는데, 배광 제어는 빛의 효율 적 사용과 연출, 그리고 빛 공해 측면에서 중요하기 때문에 적 절한 가이드라인이 필요하다. 
여의도공원의 공구별 준공도와 현황을 비교·검토한 결과, 초기 조성 계획에는 공간별 조명계획 방향이 개략적으로 제시되 었으나, 실제 세부 공간별 특성에 맞는 연출 효과는 미미했다.

\section{V. 결론}

본 연구는 도시공원의 야간경관 가이드라인을 수립할 필 요가 있다는 인식 하에 서울시 도시공원 야간경관 실태를 계 획 - 설계 과정과 설치 및 관리 현황으로 나누어 분석하여 현 상황에 대한 입체적인 원인을 규명하고자 하였다. 국내·외 야 간경관 관련 가이드라인 분석, 전문가 면담, 여의도공원의 계 획 - 설계 도서와 현장 조사를 통해 도출한 결론과 개선 방향은 다음과 같다.

첫째, 조경 분석-계획-설계 과정에서 야간경관의 연출을 더 욱 적극적으로 수용할 수 있는 방법론이 개발되어야 한다. 도 면 분석과 전문가 면담을 통해 파악한 결과, 조명 계획은 공원 의 계획 · 설계 과정에서 여전히 적극적으로 고려되지 못하고 있 으며, 설비 분야의 하위 종목으로 여전히 소극적으로 실행되고 있다. 이러한 관행은 조명이나 설비업체로 외주를 주는 방식으 로 진행되어 왔으며, 실제적인 경관 계획에서 종합적으로 다루 어지지 못하고 있는 것이 현실이다. 따라서 주간 이용을 중심 으로 하는 기존의 전통적인 공원 계획 - 설계방법론을 보완할 수 있는 야간경관에 대한 종합적인 설계방법론이 개발될 필 요가 있다.

둘째, 야간경관 평가와 계획 기준 항목을 다양화해야 한다. 현재 국내 도시공원에 적용할 수 있는 기준인 $\mathrm{KS} \mathrm{A} \mathrm{3011의} \mathrm{수}$ 평면 조도 기준은 안전성을 고려하는 최소 기준이다. 해외 관 련 가이드라인에서 살펴본 것처럼 연직면 조도, 색온도, 균제 도, 반원통형 조도, 연색성, 배광 제어등, 빛을 규정하는 다양한 항목을 통합적으로 고려해야 안전하고 쾌적하면서도 효과적인 야간경관 연출이 가능하다.

셋째, 도시공원의 수목 성장 등 내부적 요인 변화에 대처할 수 있는 설계 및 관리 방안이 필요하다. 현장 측정 조사 결과, 정해진 조도 기준을 충족시키지 못하는 공간이 공원 내에 다수 존재하였는데, 이는 조성 초기에 기준 조도를 충족하지 못했다 기보다는 25년이 넘는 기간 동안 수목 성장에 따라 빛이 가려 져 균일하게 조도를 유지하지 못하기 때문이다.

넷째, 공간별 특성에 맞는 세부 디자인가이드라인과 관련 기 준을 마련할 필요가 있다. 여의도공원의 경우, 공간의 성격과 식생의 분포, 이용 패턴 등이 상이함에도 불구하고, 대부분의 공간이 단일한 조명기구를 사용하여 공원 전체의 야간 색온도 에 따른 경관 분위기는 균일하고 단조롭게 나타났다. 연출방식 에 있어서도 공간별 특성에 맞추어 계획되었다고 보기 어려워 22 만 $\mathrm{m}^{2}$ 가 넘는 대형 공원임에도 불구하고, 여의도공원 야간경 관은 매우 획일적으로 인지되는 결과를 초래하였다.
도시공원의 야간경관은 이용자 측면에서의 안전성과 쾌적 한 조명 환경 그리고 공원의 생태적인 특성을 지닌 복합적인 개 념으로 정의할 수 있는데, 현재 25년이 지난 도시공원의 야간 경관 실태를 파악한 결과, 안전성과 쾌적성 그리고 생태적인 측면에서 분석할 수 있는 세부 기준이 마련되어 있지 않았고, 안전성과 쾌적성에 영향을 미치는 조도 역시 최소한의 기준에 미치지 못하는 공간이 많다는 사실이 확인되었다. 우리는 도시 공원의 야간경관이 안전성 차원을 넘어 도시 정체성을 형성하 고, 도시의 야간 문화를 활성화하는데 크게 기여하는 변화를 목격하고 있다. 이러한 문화적 변화에 능동적으로 대처하기 위 해서는 공원의 계획 단계에서부터 야간경관에 대한 통합적인 접근이 필요하며, 공원의 변화에 따라 적극적으로 운영해야 하 는 관리 전략까지 개발되어야 한다. 이를 위해서는 종합적인 제도와 관련 가이드라인의 개선과 세부 지침 개발이 필요하다.

본 연구는 야간경관의 중요성이 대두되는 시대적 배경에서 기존 도시공원의 야간 환경이 가지는 문제점을 제도와 절차적 인 측면과 더불어 현장 분석에 근거한 개선 방향을 제시하였다. 20 년이 넘은 대다수의 도시공원은 설계도서가 남아있지 않아 더 많은 공원을 분석 대상으로 진행하지 못한 점과 쾌적성이라 는 심미적이며, 정성적인 항목을 구체적인 지표를 통해 분석하 지 못한 점 그리고 공원의 변화하는 생태적 특성인 수목과 조 명의 관계성을 구체적으로 다루지 못한 점은 연구의 한계로 볼 수 있다. 이러한 문제점과 개선 방향, 한계점에 대한 심도 있는 고찰을 토대로 도시공원의 야간경관을 디자인하기 위한 목표 와 개념의 설정, 다양한 요소들의 도출, 그리고 구체적인 가이 드라인을 수립하기 위한 후속 연구가 필요하다.

주 1. 수평면 조도( $\mathrm{E}_{\mathrm{H}}$, horizontal illumination): 어느 점의 조도의 연직 성 분. 이 점을 통하는 수평면에 수직이기 때문에 이와 같이 부른다.

주 2. 연직면 조도( $\mathrm{E}_{\mathrm{v}}$, vertical illumination): 어떤 점의 조도의 수평 성분. 이 점을 통하는 연직면에 수직이기 때문에 연직면 조도라 한다.

주 3. 주 이용자 그룹의 과반수에 대한 시각적인 나이를 의미한다.

주 4. 일반적인 조명의 색온도 범위는 다음과 같다. 일출 직전 $(2,200 \mathrm{~K}$, 촛불의 광색 $)$-일출 40 분 후 $(3,000 \mathrm{~K}$, 고압 나트륨 램프)-일출 2 시간 후 $(4,000 \mathrm{~K}$, 백색 형광등)-정오 $(5,800 \mathrm{~K})$-흐린 날의 하늘 $(7,000 \mathrm{~K}$, 주광색 형광등)

\section{References}

1. Choi, Y. C. and J. S. Kim(2001) Model on the suitable illuminance at urban neighborhood park. Journal of the Korean Institute of Landscape Architecture 29(3): 29-37.

2. Choi, Y. S. (2008) Study of Environmentally Friendly Exterior exterior illuminationlllumination and Influences on the Ecosystem(plant) by Lighting Effects. Master's Thesis, Hanyang University, Korea.

3. Commission Internationale de l'Eclairage(2000) CIE Technical Report 136:2000, Guide to the Lighting of Urban Areas, Austria.

4. Commission Internationale de l'Eclairage(2003) CIE Technical Report 150:2003, Guide on the Limitation of the Effects of Obtrusive Light from Outdoor Lighting Installations, Austria. 
5. DiLaura, D. L.(2011) The IES Lighting Handbook 10th Edition, Illuminating Engineering Society of North America,

6. Divall. B.(2000) Uplighting Guide, Landscape Design, 5.

7. Enforcement Decree of the Act on the Prevention of Light Pollution due to Artificial Lighting, Ministry of Environment, Korea..

8. Enforcement Rule of Act on Urban Parks, Greenbelts, etc., Ministry of Land, Korea.

9. Enforcement Rule of the Act on the Prevention of Light Pollution due to Artificial Lighting, Ministry of Environment, Korea.

10. Hwang, H. L.(2011) A Study on Design to Reduce Light Pollution: Based on the Street Lighting of Residential Areas in Gang dong-gu, Seoul. Master's Thesis, Hongik University, Korea.

11. Japanese Standards Association(2010) JIS Z 9110:2010, General Rules of Recommended Lighting Levels, Japan.

12. Jo, S. D. (2001). A Study on The Landscape Lighting Planning in Outdoor Spaces; A Case of Kangwon National University. Master's Thesis, Kangwon National University, Korea.

13. Kim, J. H.(2013) Boramae Park Renovation Plan for Night Use Activation. Master's Thesis, Seoul National University, Korea

14. Korea Landscape Council(2011) A Study on the Establishment of Lighting Guidelines for to form Comfortable Nightscape.
15. Korean Industrial Standards(1993) KS A 3011, Illuminance Standards, Ministry of Trade, Industry and Energy Korean Agency for Technology and Standard, Korea.

16. Landscape Design Standards(2002), Ministry of Land, Infrastructure, and Transport, Korea.

17. Lee, J. B. (2015) A Study on Public for CPTED Concent of Parks; Targeting Daegu Dalseogu Neighborhood Parks. Master's Thesis, Keimyung University, Korea.

18. Lee, J. H.(1998) A Basic Plan of Urban Landscape in Incheon, Incheon Development Institute, Korea.

19. Lee, M. G.(2013) A Study on Lighting Control Technologies in Space for Preventing Light Pollution. Master's Thesis, Kyunghee University, Korea.

20. Management Office of Yeouido Park(1999) As-Built Drawings for Yeouido Park, Korea

21. Moyer. J. L.(1992) Landscape Lighting, Handbook of Advanced Lighting Technology, Springer International Publishing Switzerland.

22. Yang, J. S.(2016) The Post-Occupancy Evaluation of Landscape Lighting Design in Urban Parks. Ph.D. Dissertation, Ewha Womans University, Korea.

Received : 06 November, 2017

Revised : 05 December, 2017

02 March, 2018

(1st)

(2nd)

Accepted : 02 March, 2018

3인익명 심사필 